\title{
A performance solo e o sujeito autobiográfico
}

\author{
Ana Bernstein
}

$\int$

urante os anos 70, a arte da performance e a body art exploraram, de maneiras inesperadas e provocativas, o colapso dos limites entre vida e arte provocado inicialmente pela Action painting, a arte conceitual, e os Happenings dos anos 60, trazendo para o processo de produção e de recepção da arte um significado totalmente novo.

Da mesma forma que os Happenings, a performance e a body art exibem uma flexibilidade estrutural e uma indefiniçãao que rompem com a convencionalidade e as restrições formais das práticas tanto do teatro quanto das artes visuais.

Conceitualmente, a arte da performance é complexa e polêmica, não apenas porque abriga uma multiplicidade de formas, mas também porque, enquanto "gênero", tem estado em permanente transformação desde o seu surgimento. O forte conteúdo de artes visuais que apresentava no início deu lugar, ao longo das duas últimas décadas, a uma performance mais orientada pela narrativa.

A despeito dessa flexibilidade conceitual, pode-se afirmar que um dos traços principais da arte da performance é o seu caráter autoral. $\mathrm{Na}$ cena teatral, o que se tem é um personagem já escrito que é trazido à vida por um ator; pode ser descrita, portanto, como uma citação na qual a natureza fictícia do personagem e de suas ações é evidente. Justamente por esta razão é que J. L. Austin exclui a representação teatral de sua definição de elocuçôes performativas, rotulandoa de parasitica. Austin observa que a elocução performativa dita por um ator no palco é nula ou vazia, uma vez que ele não $f a z$ alguma coisa, mas representa uma ação. A função do ator é portanto interpretativa.

$\mathrm{Na}$ arte da performance, o performer é o autor do seu próprio script. Além do mais, a performance quase sempre exibe uma forte atualidade e é bastante responsiva às questóes políticas e sociais do momento. Diferentemente do ator teatral, o performer não pretende representar um outro e habitar um espaço e tempo fictícios. Como Lynda Hart apropriadamente observa, "a arte da performance não permite a percepção da distância entre o performer e sua linguagem e gestos, que o ator possui automaticamente através do uso histórico do 'personagem'" (Hart, 1996, p. 115-6). A razão dessa dificuldade em distanciar o performer de sua linguagem

Ana Bernstein é crítica e pesquisadora de teatro, formada pelo Centro de Letras e Artes da Uni-Rio, com Mestrado em História Social da Cultura pela PUC-RJ. Atualmente cursa o Doutorado em Performance Studies na New York University. 
e gestos reside precisamente no fato de que na performance as funções do artista, autor e persona estão fundidas. Além disso, a fusão do autor e performer é ainda mais complicada pela imbricação do sujeito e do objeto, tanto pelo uso do corpo como um lugar de representação quanto pelo emprego freqüente de material autobiográfico.

A body art e arte da performance, com seu caráter multidisciplinar, exigem que as relações entre artista, trabalho artístico e público sejam repensadas. $\mathrm{O}$ corpo atuante e quase sempre despido do artista tornou-se não apenas o veículo para o trabalho, mas o objeto de arte em si. Artistas como Marina Abramovic e Chris Burden criaram performances nas quais eles puxaram seus corpos ao limite extremo da dor e da resistência física e emocional. Carolee Schneemann fez do corpo erótico, sexual, o objeto principal da performance em trabalhos como Meat Joy (1964) e Interior Scroll (1975), usando seu corpo como "material integral" do seu trabalho. O modo de recepção passa, portanto, da observação de um objeto de arte contido em si e independente de seu criador, para uma relação intersubjetiva com o sujeito encarnado do artista em processo de produção do trabalho, trazendo à luz "a relação entre visão e significado, entre o ato de fazer e o ser", nas palavras de Kristine Stiles (1998, p. 228). O corpo tornase então o ponto de mediação entre uma série de relações binárias de oposição, tais como o interior e o exterior, sujeito e mundo, público e privado, subjetividade e objetividade. $\mathrm{O}$ corpo é o lugar em que essas contradições ocorrem.

O intenso interesse pela autobiografia demonstrado pela arte da performance, particularmente em trabalhos solos, pode parecer, a priori, apenas um sintoma da profunda preocupação com o sujeito que marca a modernidade. A autobiografia é geralmente entendida como algo privado, como um olhar que se volta para $o$ interior de si mesmo. A performance solo autobiográfica, no entanto, como eu pretendo demonstrar nesta apresentação através do exame comparativo dos trabalhos de Karen Finley, Peggy
Shaw e Penny Arcade, possui um forte caráter público. Contrariamente à idéia de uma armadilha em auto-absorção que Richard Sennett define como "narcisismo" e que leva à inação do corpo social, uma parte significativa da arte da performance nos Estados Unidos nas últimas duas décadas vem intervindo politicamente de maneira significativa e constante na esfera pública. A teoria e as práticas feministas têm sido inestimáveis nesse processo, e isso explica, em parte, porque as três artistas analisadas neste trabalho são mulheres. A performance solo autobiográfica tem, de fato, desempenhado uma função crítica na criação de um espaço discursivo para minorias que não se enquadram na normatividade do discurso ideológico dominante. Para aqueles relegados ao silêncio dentro do discurso dominante, a performance solo autobiográfica tem sido instrumental para a reivindicação por diversas minorias do papel de agentes sociais e na criação de uma "contra-esfera pública". Afinal, como Foucault postula, se "o discurso pode ser tanto um instrumento e um efeito do poder", ele pode também funcionar como "um obstáculo, uma pedra no caminho, um ponto de resistência e um ponto de partida para uma estratégia oposicional. O discurso transmite e produz poder, reforça o poder, mas também o enfraquece e o revela, torna-o frágil e faz com que seja possível obstruílo" (Foucault, 1990, p. 101).

\section{Tratamento de choque: o trabalho de Karen Finley}

"I'm living in hell and I intend to keep my devil out"

Karen Finley.

Ela entra vestida de noiva, a mais idealizada imagem feminina para sempre cristalizada. A longa cauda do vestido, porém, está embrulhada no seu braço, que a carrega como se uma fosse uma sacola de compras, enquanto ela limpa o espaço com um aspirador de pó durante sua entrada. De pé, bem próxima à primeira fileira 
de espectadores, ela desliga o aspirador e dá início a uma digressão sobre o perfil psicológico sadomasoquista de Winnie the Pooh e sua turma, estabelecendo uma empatia imediata - e uma certa intimidade - com o público.

Servindo como contraponto para sua fala, o aspirador de pó é ligado e desligado, criando pausas, marcando o início de uma nova passagem ou a retomada de um pensamento. A fragmentação deste momento ilustra o espírito do trabalho. The American Chestnut, o penúltimo trabalho de Karen Finley, é uma colagem de vários monólogos que se juntam para formar um todo orgânico. O caráter de assemblage do trabalho não nos deixa esquecer que Finley é também uma artista plástica que trabalha com instalações. Nesse sentido, vídeo e projeção de slides possuem tanta importância para a composição do trabalho quanto o corpo nu ou seminu da performer: são todos elementos da mesma linguagem.

O trabalho de Finley é ao mesmo tempo extremamente pessoal e profundamente político. Uma grande parte de seus textos segue uma linha confessional e é escrito, portanto, freqüentemente na primeira pessoa do singular: Frases do tipo "Deixa eu lhe contar a respeito de...", "Eu sonhei...", "Eu me lembro..." ou "Eu fiz..." são tão recorrentes em seu trabalho que se tornaram uma de suas características mais distintas.

Ainda assim a maneira como Finley emprega o material autobiográfico não se enquadra na definição de Philippe Lejeune de autobiografia e do pacto autobiográfico. De acordo com o teórico francês, autobiografia é uma "prosa narrativa retrospectiva escrita por uma pessoa real a respeito de sua própria existência, onde o foco se encontra na sua vida individual, na história particular de sua personalidade" (Lejeune, 1989, p. 4). A autobiografia pressuporia, portanto, um contrato entre o autor e o leitor que deveria ser a afirmação, no texto, da identidade do nome próprio, da assinatura do autor, com o narrador e o protagonista.

Embora Karen Finley fale de coisas íntimas, de experiências pessoais de vida, e até mes- mo as exiba visualmente - como acontece em The American Chestnut com as imagens do seu parto projetadas em um tríptico de slides e mostrando a cabeça de um bebê saindo de uma enorme vagina -, ela também incorpora uma multiplicidade de vozes à sua própria. Seu trabalho não é uma prosa narrativa strictu senso, uma vez que seus monólogos são uma mistura de prosa e poesia e podem ser escritos tanto na primeira quanto na terceira pessoa, de um ponto de vista feminino ou masculino. $\mathrm{O}$ foco da sua "narrativa" não é nunca na sua vida individual per se ou na sua personalidade. Mais precisamente, os limites entre autobiografia e ficção são problematizados. A mesma incerteza cerca a tríade autor-narrador-protagonista. Estórias pessoais são reescritas, reinventadas, e misturadas com ficção na performance. É o caso, por exemplo, do suicídio do pai de Finley. Finley nunca representa o suicídio de seu pai em si, mas em mais de um de seus monólogos há um pai que se mata. Ela cria diferentes cenários e contextos para isso, como em The Constant State of Desire e em We Keep Our Victims Ready, mas o fato real está presente apenas como subtexto e não está sujeito à verificação factual.

Grande parte do poder do trabalho de Finley vem da falsa impressão que dá de que é uma fala saída diretamente do inconsciente, como um fluxo de idéias abrupto, impolido, não censurado. A crítica teatral C. Carr definiu esta fala como uma "Fala do Id". Para Lynda Hart, "a linguagem de [The Constant State of] Desire, sua lógica não seqüencial, suas mudanças abruptas, suas disjunções e deslocamentos, sua raiva freqüentemente incubada, imita a linguagem do inconsciente, trazendo para o primeiro plano a famosa afirmação de Lacan de que o inconsciente é estruturado como linguagem” (Hart, 1996, p. 112).

A impressão de um fluxo de idéias fluindo direto do inconsciente é reforçada ainda mais pelo caráter não estudado, incompleto da performance. Finley não possui nenhuma técnica de atuação e nunca ensaia seus trabalhos antes de apresentá-los ao público, a fim de não perder 
a espontaneidade. Ela geralmente cerra os olhos durante a performance de um monólogo - e sua voz se transforma numa espécie de lamento ou transe encantatório. Se por um acaso ela esquece o texto, ela simplesmente pega o script e o lê. Finley descreve seu processo de trabalho da seguinte maneira:

"Todos os meus trabalhos são work-in-progress: cada noite que eu faço um trabalho (...) eu experimento algumas coisas para mim mesma. Eu não ensaio minhas performances. Meu show pode fracassar quando eu vou para o palco. (...) Eu não planejo a ordem das cenas. A única coisa que faço de antemão é escrever o meu script. (...) Mas eu posso sempre descartar o script.

(...) Durante a performance eu tento deixar todas as diferentes vozes que estão na minha cabeça serem ouvidas. Eu digo aquilo que geralmente não é dito numa performance - $\mathrm{o}$ que está passando na minha cabeça naquele momento. Eu não me censuro. $\mathrm{O}$ mundo da minha performance é esse mundo interior dentro de mim, dentro de qualquer um.

É por essa razão que eu lido com muita informação pessoal em meus trabalhos. Quando eu comecei a trabalhar com performance, eu falava muito sobre autismo e suicídio. Eu queria usar coisas que aconteceram na minha vida pessoal ou ao redor dela. (...) Eu quero explorar isso ainda mais nesse momento. Eu planejo continuar colocando meus sentidos, minha raiva e emoções na performance" (Finley, 1999, p. 486).

Essa sensação de fluxo incontrolado é, além do mais, intensificada pelo conteúdo "pervertido" do seu trabalho. As performances de Finley são normalmente violentas, escatológicas e profundamente perturbadoras. Ela fala sobre pais que estupram suas próprias filhas ou que abusam sexualmente das amiguinhas de suas filhas, filhos fodendo suas mães, netos sodomizando suas avozinhas com inhames, mulheres espancadas por seus maridos, mães que matam seus bebês. Ela fala de merda, porra, urina e comida.
Ela esfrega seu corpo nu com chocolate e lambuza sua bunda com inhame. Seus monólogos têm títulos do tipo "I'm an ass man", "strangling baby birds", "cut off balls", "fist fuck", e "Vomit Belly", para citar alguns.

A agressividade do seu trabalho está certamente mais de acordo com o teatro da crueldade de Artaud do que com a idéia tradicional de que a experiência estética produz prazer. Finley não procura agradar ninguém. A violência de suas performances freqüentemente provocava reações também violentas do público já intoxicado de bebida nos clubes de performance em que Karen Finley se apresentava nos fins de noite no começo de sua carreira, nos início dos anos 80. Os homens freqüentemente a insultavam e, por vezes, reagiam fisicamente durante a performance. C. Carr descreve algumas dessas reações em seu artigo Unspeakable Practices, Unnatural Acts:

"Finley apareceu de súbito no palco, por volta de uma hora da manhã, trajando um vestido de baile de mau gosto. Durante horas a multidão punky entorpecida vinha se afogando em bebida. Com sua habitual postura de confrontação, Finley gritou, 'Vocês, seus tipinhos vestidos de couro com cabelo espetado, eu adoro pensar em vocês se masturbando!'

Ela lhes disse como ia colocar uns pêssegos na sua buceta, e então pegar um desses filhos da puta e colocá-lo sob seu vestido de festa e dizer a ele, 'Baby coma esses pêssegos e creme' e então ela iria fazer uma visita às freiras porque 'Eu não consigo dormir a menos que eu escute o som de xoxota', o que ela seguiu com (...) o número de merda líquida ('O que eu faço é, eu chupo, baby.') Ela pontuou o momento derramando um vidro de calda de chocolate Hershey no seu vestido.

Uma onda poderosa de histeria correu pela multidão. Dois rapazes jovens perto de mim estavam se contraindo e soltando guinchos e dobrados em dois. Finley então levantou seu vestido e mostrou a bunda nua para o público e anunciou: 'Isto é Inhame no Traseiro da 
Minha Vovozinha'. 'OH DEUS!', gritou um dos homens perto de mim. Ele e seu amigo começaram a atirar cigarros acesos em Finley. Eles estavam totalmente fora de controle" (Carr, 1993, p. 125).

Tabus tais como orifícios corporais, relações incestuosas e diferentes tipos de perversão sexual, constantemente endereçados em seus monólogos, conferem ao seu trabalho um valor de choque. Finley não diferencia entre atos tais como comer, cagar, trepar ou vomitar. Nesse sentido, seu trabalho pode ser definido como rabelaisiano, já que ela explora o corpo em seu extremo grotesco. Em suas performances, tudo é excessivo e degradante. Como em Rabelais, para quem a principal característica do corpo grotesco é sua "natureza incompleta e aberta, e sua interação com o mundo", "revelada de forma mais concreta e completa na ação de comer" (Bakhtin, 1984, p. 281), os monólogos de Finley exibem sempre um consumo e excreção de comida imoderados e transgressivos, associados com corpos impuros. Os limites entre o interior e o exterior, entre orifícios usados para o consumo e excreção de comida e para atos sexuais são permanentemente confundidos, como no monólogo Refrigerador:

"E a primeira, e a primeira, e a primeira memória, memória que tenho, que tenho de meu pai é dele me colocando no refrigerador. Ele tinha o hábito de tirar toda minha roupa do meu corpo de cinco anos de idade e eu ficava sentada nua naquela prateleira prateada da geladeira. (...)

Então ele se abaixava em direção à gaveta dos legumes, abria a gaveta e tirava as cenouras, $o$ aipo, a abobrinha, os pepinos. E então ele começava a trabalhar o meu buraquinho, meu pequeno buraquinho, meu pequeno pequeno buraquinho. Meu buraquinho de menina. Me mostrando 'como é ser como a mamãe', ele diz. Me mostrando 'como é ser uma mulher, ser amada. Essa é uma tarefa para o papai', ele me diz. Trabalhando meu buraquinho. (...)
Então eu ouço minha mãe chegar em casa. E ela começa a gritar, com todos os pulmóes. 'O que aconteceu com os legumes do jantar de hoje? O que aconteceu com os legumes? Você andou brincando com sua comida de novo, menina? Eu ia fazer a receita favorita do seu pai.'

Eu apenas quero gritar, mas não posso, claro, 'Mamãe, abra seus olhos! VOCÊ NÃO SABE QUE EU SOU A FAVORITA DO PAPAI?" (Finley, 1990, p. 20-1).

A violência verbal e visual que marca o trabalho de Finley possui também um importante aspecto construtivo, porque toma uma posição política, que não pode ser separada de questôes feministas e de gênero sexual. A degradação do corpo em suas performances, seja a violação do estupro ou a exibição do corpo feminino nu coberto de imundície, traz para o primeiro plano questôes de abuso e discriminação da mulher na sociedade patriarcal. Ao mesmo tempo, desfaz conscientemente a imagem feminina idealizada, associada com limpeza e maternidade. O choque de ver essa mulher branca, desejável, bonita, degradando seu corpo ou falando sujo sobre orifícios anais, tem sido não somente apontado pela imprensa, que não hesitou em chamar suas performances de doentias e definila como uma histérica, mas acabou resultando também no cancelamento de seu patrocínio pelo National Endowment for the Arts. Finley traz para a esfera pública o que é normalmente confinado à esfera privada e portanto sobre controle. Nesse sentido, seu trabalho se afina com a política feminista de que "o pessoal é político" e que as esferas pública e privada não estão dissociadas mas sim interligadas e permeadas por relaçôes de classe, gênero sexual e sexo. Portanto, ao invés de ser uma voz isolada e voltada para si mesma, a narrativa autobiográfica na performance solo funciona como um instrumento público na criação de um senso de comunidade.

Os monólogos de Finley estão, por conseguinte, imersos em um drama duplo: psicanalítico e político. Eles abordam questões como a política que envolve a epidemia de Aids, 
o direito ao aborto, o racismo, a misoginia e a homofobia, bem como as relaçôes de poder. Finley dá voz às mulheres, às minorias étnicas e sexuais, aos desabrigados. Ela incorpora essas vozes como se fossem a sua própria, misturando-as com estórias pessoais, memórias e experiências. $\mathrm{O}$ resultado é um texto polifônico no qual o dialogismo surge como uma estratégia consciente da narrativa. Essas elocuções cheias de ecos de palavras de outras pessoas, são encontradas às vezes dentro de um mesmo monólogo, como Strangling Baby Birds, onde o narrador muda abruptamente da terceira para a primeira pessoa do singular. Essa polifonia pode ser também ouvida na mudança de vozes e de diferentes posicionalidades do sujeito de um monólogo para o outro, entre os textos que se juntam para formar um trabalho em particular. E no entanto essas vozes não são personagens teatrais, não são nem mesmo claramente delineadas. No "estado de transe" em que Finley atua, essas diferentes vozes, como nota C. Carr, "fluem de uma para a outra durante o curso de um monólogo na medida em que este se move de um estado emocional para o próximo, os deslocados gêneros sexuais e narrativas mantendose juntos por uma lógica febril de sonho" (Carr, 1993, p. 130).

Finley freqüentemente refere-se a si mesma em performance como uma médium, um veículo para que coisas possam sair de dentro de si ou penetrar o seu interior, como se, nesse transe, sua psiquê fosse revelada ao público sem mediação, num aparente fluxo espontâneo. Contudo, esse "transe" não cancela ou aliena a presença autoral, pois sabemos que essa espontaneidade é um efeito adquirido por uma narrativa construída de forma consciente e cuidadosa.

Não se pode, portanto, descrever o trabalho de Finley como uma narrativa linear que busca dar, em retrospecto, um senso de continuidade e unidade ao sujeito autobiográfico. Mais precisamente, o que vemos é a narrativa inacurada de um sujeito fragmentado que se abre para e se identifica com múltiplas vozes. $\mathrm{O}$ sujeito autobiográfico é, por conseguinte, cons- tituído no próprio processo da escrita, através da polifonia de seus textos. É este contínuo diálogo interior entre o sujeito e o outro que faz com que essas vozes tornem-se a voz própria de Finley. Nesse sentido, não importa se as estórias narradas foram de fato vividas ou não por Finley. A verdade autobiográfica não deriva do aspecto referencial de seus textos, ela é igualmente fabricada por eles. Karen Finley pode então dizer, como o artista performático Tim Miller em seu solo autobiográfico Sex/Love/Stories: "Eu lembro de tantas coisas, algumas delas até mesmo aconteceram" (Román, 1998, p. 143).

\section{Há um animal dentro de mim: o trabalho de Peggy Shaw}

"I'm just thousands of parts of other people mashed into one body"

Peggy Shaw

Menopausal Gentleman, o último solo de Peggy Shaw, é um trabalho que se baseia no que parece ser, a princípio, uma contradição em termos, enunciada pelo provocativo título. Enquanto o primeiro termo designa um fenômeno biológico geralmente relacionado no imaginário público ao sexo feminino - ainda que a menopausa masculina seja um fato cientificamente provado -, o último se refere a uma qualidade associada exclusivamente à masculinidade. Ele descreve um comportamento (especialmente em relação às mulheres) que está de acordo com um conjunto de regras representativo dos altos preceitos da sociedade. Nesta performance, porém, gentleman está associado a um tipo diferente de masculinidade, a do sapatão, geralmente considerada ultrajante pelo normativo heterossexual.

A contradição textual tem um paralelo visual no material de divulgação da performance: uma fotografia de uma mulher madura vestindo uma calça de homem com suspensórios, mas sem camisa, deixando à mostra seus seios nus. Sua mão direita está enfiada por dentro da 
calça surgindo novamente através do zíper aberto, parando em frente ao seu sexo, enquanto a mão esquerda descansa em sua coxa, por sobre a calça. Essa imagem se abre a diferentes interpretações: a mais óbvia é a imagem da mulher fálica, na qual a mão emerge da abertura do zíper como um pênis. No clássico discurso psicanalítico, é a imagem da lésbica que se apropriou do pênis abertamente sem se preocupar em disfarçar o fato por meio de uma máscara de feminilidade. Ao mesmo tempo, sugere um gesto auto-erótico, o ato de tocar a si mesma por prazer, afirmando, portanto, o desejo sexual e a agência da mulher. É possível lê-la ainda como cobrindo o seu sexo: um sexo que não pode ser visto, sugerindo simultaneamente a invisibilidade da Mulher (que não é senão o espelho do homem) e a invisibilidade da sexualidade lésbica, fundida aqui sob o signo "sexo". Uma fusão produzida pela polissemia da palavra sexo, usada tanto para denotar o sexo biológico quanto identidades de gênero e práticas sexuais.

O close up da fotografia deixa de fora da moldura o que se encontra acima dos ombros e abaixo da área próxima à genitália. Dentro da moldura, porém, e da mesma forma como acontece com o título do trabalho, encontramos as categorias de masculino e feminino condensadas e indistintas, abalando a visão normativa do sistema binário sexual, em que o masculino é atributo exclusivo do homem e o feminino da mulher. Ao declarar a si mesma um gentleman em menopausa, Peggy Shaw está não somente torcendo a linguagem em direçôes inesperadas, mas também questionando classificaçôes "naturais” de gênero sexuais. De fato, essa única imagem epitomiza a complexidade das questôes levantadas pelo seu trabalho.

Em seu ensaio The Style of Autobiography, Jean Starobinski escreve que "alguém dificilmente teria motivo suficiente para escrever uma autobiografia não fosse alguma mudança radical ocorrida em sua vida (...). É essa transformação interna do indivíduo - e o caráter exemplar dessa transformação - que fornece ao sujeito o discurso narrativo no qual o 'Eu' é ao mesmo tempo sujeito e objeto" (Starobinski, 1972, p. 78).

Em Menopausal Gentleman, Peggy Shaw descreve uma tal transformação nos seguintes termos, como abertura de sua performance:

"Eu estava andando e me encontrei abraçada
a uma árvore no centro da cidade. A árvore
se chocou contra meu peito e fez com que eu
perdesse o fôlego. Antes de eu cair, antes que
eu diminuísse o passo por meio da pancada
com a árvore, eu aparentava ser perfeitamen-
te normal. Há maneiras melhores de se dimi-
nuir o passo". A colisão com a árvore é, claro, uma metáfora escolhida por Shaw para descrever o impacto e o caráter inesperado de uma experiência de vida transformadora e de uma literal transformação interna: menopausa. Menopausal Gentleman é uma reflexão sobre o medo de envelhecer e as transformações físicas e emocionais provocadas pela menopausa. Peggy Shaw examina o que significa ser sapatão - ou, como diz o título, um gentleman - e passar pelo inevitável processo menopausal; o que significa vivenciar uma violenta mudança física. Perturbadora e problemática para a maioria das mulheres, a menopausa pode ser ainda mais estressante para o sapatão que, a despeito do seu sexo biológico, marca seu gênero sexual como masculino. "É difícil ser um gentleman em menopausa", Peggy Shaw confessa ao público.

Da mesma forma que a imagem de divulgação deixa de fora da moldura precisamente o rosto de Peggy Shaw, aquilo que a individualiza, e revela apenas um corpo de mulher, Menopausal Gentleman é um trabalho que, embora largamente autobiográfico, abre a discussão sobre questôes de gênero e sexualidade, sobre o controle político e ideológico imposto pelo Estado sobre o corpo da mulher, sobre o valor de uso de corpos produtivos e improdutivos, de construções de identidade. Torna-se claro, dessa forma, como assuntos íntimos e pessoais de sujeitos/corpos individuais são constituídos pela 
interseção de várias práticas culturais e se imbricam com o corpo político.

Peggy Shaw emprega um tom diretamente confessional, deixando claro desde o início a natureza autobiográfica de sua performance:

"Deixe eu tentar descrever para você... como tudo se parece e como tudo acontece dentro do meu corpo, do crepúsculo ao alvorecer da noite do meu corpo. Eu estou tentando passar por uma pessoa quando há um animal dentro de mim, um animal em fogo que espera pelas sombras da noite. Andando e suando e girando, uma fera em cativeiro dentro do meu corpo, exaurindo os sulcos do meu chão" (Shaw, 1997).

Ao invés da usual narrativa que vai do nascimento ao tempo presente da escrita esperada da maioria das autobiografias, Menopausal Gentleman cobre um período de tempo que vai "do crepúsculo ao alvorecer da noite do corpo" de Peggy Shaw. Que a temporalidade da narrativa seja determinada de acordo com o corpo da autora/narradora/performer, faz todo o sentido, uma vez que tanto a narrativa quanto a performance são estruturadas ao seu redor. Peggy Shaw engaja cada membro, cada parte do seu corpo para falar de amor, desejo, perda e medo.

O corpo é tratado não apenas no seu aspecto físico, menopausal, mas também como limiar, como ponto de mediação entre o público e o privado, como meio de comunicação entre o que está dentro e o que está fora, como subjetividade encarnada. Shaw usa sua sapatice para desfazer a fusão de sexo, gênero e sexualidade, e para tornar claro como significados culturais são inscritos no corpo. Ela explora as antinomias entre aparência e essência, normal e anormal, interior e exterior, entre representações construídas e verdades íntimas.

"O interior do meu corpo", diz Shaw, "parece tão frágil. Eu sempre tive medo de colocar meus dedos dentro de mim. Engraçado como o sexo da mulher é do lado de dentro, o do homem do lado de fora. É o jeito que as coisas são. Meu corpo está dentro desse terno. $\mathrm{O}$ terno dá a vocês uma idéia de como eu me sinto. Por dentro eu estou toda enfaixada, porque você não pode ter um terno excelente como esse e ter calombos do lado de fora".

Com um clássico humor camp, ela revela o quão cuidadosamente "constrói" seu gênero de forma que o exterior corresponda ao seu sentimento interior.
"Ser um gentleman é muito importante para mim... Eu tenho que me concentrar para manter minha voz baixa, para combinar com meu terno. (...) Você tem que gastar um bo- cado de tempo sendo um gentleman. Eu sou o gentleman trabalhador que dá mais duro no show business. (Ela cospe como homem) Ser um gentleman significa que meus sapatos estão brilhando. Sapatos são um dos elementos de um gentleman. E abotoaduras. E assovio".

Shaw não está afirmando que o gênero sexual é performativo no sentido volitivo. Como Judith Butler bem observa, "um sujeito tão voluntarioso e instrumental, alguém que decide a respeito do seu gênero, claramente não é seu gênero desde o princípio e falha em reconhecer que a sua existência já é decidida pelo gênero" (Butler, 1993 b, p. x). O gênero é performativo apenas no sentido em que "constitui como um efeito o próprio sujeito que aparenta expressar" (Butler, 1993a, p. 314). Por meio da performance, entretanto, Peggy Shaw torna seu gênero visível, passível de leitura, para o público. Ela conscientemente questiona o sistema binário de gêneros, ao mesmo tempo em que reivindica uma identidade constituída através do desejo. Shaw não está tentando passar por homem, sua sapatice não é uma afetação nem uma mascarada, como ela explica humoristicamente:

"Eu nasci assim. Eu nasci sapatão. Eu não aprendi a ser sapatão na escola de teatro. Eu sou tão queer que eu não tenho que falar a respeito. Isso fala por si mesmo".

A questão de "passar" é importante e complexa. No sistema binário de gêneros, a heterossexualidade é não apenas naturalizada, mas se torna 
de fato, compulsória, e sexualidades e gêneros que escapam a este modelo são classificadas como patológicas e perversas. Dentro de tal estrutura, é quase impossível para a masculinidade do sapatão ser reconhecida como outra coisa que não a mera imitação da masculinidade heterossexual. Em Imitation and Gender Subordination, Judith Butler chama atenção para o fato de que não há tal coisa como "um gênero próprio a um sexo e não à outro" e conclui que gênero é portanto "um tipo de imitação para o qual não há original” (Butler, 1993a, p. 313-4), ainda que a heterossexualidade compulsória tente sempre instituir-se como norma. Como Shaw demonstra em sua performance, a masculinidade não é propriedade do homem e não concerne apenas a um modelo heterossexual. $\mathrm{O}$ sapatão deixa então de ser uma imitação e se afirma como a articulação de uma masculinidade da mulher, tornando possível imaginar gêneros sexuais diferentes daqueles já legitimados.

Relacionado com a menopausa, o problema de "passar" abre-se ainda a uma outra dimensão. Submetido a uma série de transformaçôes fora do controle do consciente, o corpo em menopausa revela-se como um corpo indisciplinado, improdutivo, dando origem a medos em relação à insanidade, à degeneração física, e ao declínio sexual, gerando um grande nível de ansiedade em relação ao futuro. Em regra, as mulheres tendem a não admitir publicamente essa mudança. Geralmente apresentada de forma negativa e até mesmo patológica, a imagem retórica "ligada à menopausa é a do colapso do controle central" (Martin, 1997, p. 34), como Emily Martin torna evidente em seu estudo Medical Metaphors of Women's Bodies, em que a autora analisa o uso da linguagem médica em relação ao corpo das mulheres ${ }^{1}$. A menopausa constitui-se então como uma questão privada, pessoal e muito íntima, a ser discutida apenas dentro dos limites do consultório médico ou da esfera doméstica. Algumas mulheres consideram mais desejável passar como perfeitamente funcional, escondendo do mundo externo a transformação interna, mantendo-a "dentro do armário". Passando por straight quando de fato se sentem queer. Nesse sentido, a postura "perfeitamente funcional" é uma performance $d r a g$ como outra qualquer, que depende apenas da economia entre o visível e o invisível.

A importância de Menopausal Gentleman reside precisamente em discutir essas questôes, quase nunca tratadas em público, a menos que seja dentro dos limites seguros do discurso médico ou a serviço dos interesses das corporaçōes farmacêuticas. A narrativa autobiográfica de Shaw confere visibilidade à menopausa, emprestandolhe o peso de um sujeito encarnado. Da mesma forma que os grupos de conscientização da mulher dos anos 70 encorajaram a exposição pública de questôes pessoais, a performance confessional de Shaw cria um vínculo entre performer e público, baseado no reconhecimento de experiências compartilhadas. Ela permite ao público rir da menopausa e das políticas sexuais,

1 Qualquer sumária descrição médica sobre menopausa informa-nos que a redução aguda dos níveis de hormônios produzidos pelo corpo "pode causar conseqüências ao mesmo tempo agudas e crônicas em tecidos dependentes de hormônios tais como o cérebro, os ossos, o coração, os vasos sanguíneos e a pele" (Endocrinology and Menopause - documento produzido pela Endocrinology Society e publicado em seu website). Os efeitos mais comuns são ondas de calor, suores noturnos, instabilidade emocional, ressecamento da vagina e da vulva, atrofia vaginal (resultando em dor durante o ato sexual), irritabilidade, insônia, perda de memória, incontinência urinária, enxaquecas, cansaço, risco de doenças do coração, aumento do risco de osteosporose, do mal de Alznheimer, risco de câncer colo-retal, flutuações no desejo sexual e depressão (essa informação está disponível em diferentes websites sobre o assunto. Os dados utilizados foram encontrados em The Foundation for Better Health Care e The North American Menopause Society). 
ao mesmo tempo em que incentiva uma reflexão crítica a respeito dessas questôes. Nesse sentido, o trabalho solo de Peggy Shaw compartilha da preocupação do seu grupo teatral Split Britches sobre a necessidade de se repensar a política e a semiótica da representação da mulher no palco, visando a construção de uma visibilidade lésbica no teatro. Numa entrevista em 1986, Shaw definia o projeto do grupo em termos que podem ser tomados emprestados também para a definição do seu projeto de solo autobiográfico:

"É uma coisa muito nova ser lésbica... Então nós estamos tentando descobrir o que é a lésbica. Ou o que eu sou. Nós estamos tentando descobrir sem todas essas outras constrições e regras... tentando descobrir a respeito de todas essas vidas que tem sido escritas ao redor por tantas centenas de anos" (Patraka, 1993, p. 217).

\section{Eu sou uma perdedora: o trabalho de Penny Arcade}

"I'm writing my way out of my life" Penny Arcade (Fan Mail \#2)

No outono de 1997, Penny Arcade fez uma série de performances na House of Candles, intitulada $A$ Thousand and One Nights of Penny Arcade. A House of Candles é o que muitos chamariam de um "buraco": uma velha loja caindo aos pedaços na Rivington Street, numa parte do Lower East Side que na época ainda se parecia com uma terra de ninguém, i.e., o que o Lower East Side era antes do processo de gentrification ${ }^{2}$ que teve início nos últimos anos.

O espaço é uma espécie de corredor, e uma cortina barata divide a área da performan- ce da entrada da rua. A sala é realmente pequena, com apenas uma arquibancada improvisada para uma platéia também pequena. Não há nenhum refletor, nem palco. A distância entre a primeira fileira de espectadores e a parede descascada ao fundo da área da performance não chega a 3 metros. Ao centro, apenas um velho microfone num pedestal. À esquerda, próxima à parede, uma cadeira velha e alguns papéis espalhados no chão. $\mathrm{O}$ único banheiro fica à direita, e o público tem que atravessar o palco para ir até lá.

Embora a presença de Penny seja mágica, as estórias que ela conta em $A$ Thousand and One Nights of Penny Arcade são assustadoramente reais. A beleza das mil e uma noites, como Borges observou, reside na idéia de infinito contida no título, de incontáveis, intermináveis noites às quais se adiciona mais uma. Da mesma forma, em A Thousand and One Nights of Penny Arcade as estórias nunca terminam, elas são inumeráveis porque são estórias que estão sendo escritas todos os dias na cena artística de downtown New York, ou do que resta dela. Como Sherazade, Penny Arcade conta estórias para sobreviver.

Penny Arcade, cinqüenta anos de idade, descende, em suas palavras, "de uma longa fileira de pessoas da qual não sobrou muita gente em pé". A maioria de seus amigos e pares que fizeram a cena artística nas décadas de 60, 70 e 80 - Jack Smith, Ethyl Eichelberger, Charles Ludlam, Kevin Bradigan, David Wojnarovich, e tantos outros - ou morreram de Aids ou se suicidaram. Em seu trabalho, Penny celebra e ajuda a manter vivo o legado desses artistas agora mortos.

A Thousand and One Nights of Penny Arcade é um trabalho sobre o desaparecimento da boemia, do underground, do verdadeiro mundo artístico que está rapidamente sendo

2 Gentrification é o termo inglês usado para indicar o processo pelo qual uma determinada rua ou área habitada por populações pobres é transformada pela mudança de pessoas de classes sociais mais elevadas para esta área. Cf. Longman Dictionary of Contemporary English. 
substituído por uma cultura de mercado. As estórias da vida artística de Penny Arcade são entrelaçadas com a transformação social e política da cena cultural de Nova York, resultante de uma política conservadora de direita. Penny faz a crônica do fim de Nova York como capital cultural e o surgimento da capital do shopping mall.

"O lower east side", ela conta, "era uma Meca para os desajustados, perdedores e desviados. Nós não participávamos da cultura do mainstream. Nós permanecíamos nas laterais". "O lower east side costumava ser cheio de escritores, pintores, poetas, fotógrafos, produtores de filme, escultores, músicos, designers, junkies, putas e gente excêntrica. Agora está cheio de estudantes universitários pretendendo ser escritores, pintores, poetas, junkies, putas e gente excêntrica. Em outras palavras, os dez garotos mais populares de cada escola de segundo grau no mundo estão agora vivendo no lower east side. Essas são as pessoas que a maioria dos que se mudaram para Nova York - se mudaram para escapar delas. (...) Ouça, quando Penny Arcade é considerada a pessoa mais excêntrica downtown, há um problema!"

Penny escreve sobre a sua vida, sua vizinhança, sobre os lugares onde a boemia floresceu. Ela escreve sobre os artistas que estão sendo forçados a se mudar devido aos altos preços dos aluguéis; ela denuncia a política municipal de demolir prédios habitados por moradores de baixa renda, deixando um grande número de famílias desabrigadas e despossuídas. Ela discursa contra a política conservadora do prefeito Giuliani que nos últimos oito anos vem atacando incansavelmente não apenas as artes, mas os clubes de dança e de strip-tease, as prostitutas, os desabrigados, os pobres.

Penny conta estórias da sua geração e lamenta que a nova geração tenha parado de experimentar, não respondendo mais aos problemas políticos e sociais. Ela anuncia que a sua performance é sobre a nobreza do fracasso e o seu lento declínio. Porque "é importante fracassar em público”. Ela se declara uma perdedora, diz que vem de uma longa linha de perdedores. "Na América, dizem a todo mundo que eles vão vencer, mas todos não podem vencer! ALGUMAS PESSOAS TÊM QUE PERDER!"

Jack Smith fracassou publicamente. Penny nos conta que "ele praticamente morreu de fome. Ele morreu de Aids, mas antes disso ele passou fome por 20 anos". Os artistas de vanguarda, os poetas, os junkies, as putas, a verdadeira boemia, esses não estão preocupados em ganhar, são perdedores intencionais. O underground pode ser destruído, mas não pode ser cooptado pelo mercado, transformado em commodity. "O underground é inviolável", diz Penny. "Não é um lugar. É um espaço metafísico. O underground é onde a boemia encontra o submundo, o mundo do crime. Se você não tem uma classe criminosa funcionando na sua cena artística - você tem academia”.

Mais do que qualquer outro artista performático, o trabalho de Penny demonstra a indefinição dos limites entre vida e arte. Em Bad Reputation, um trabalho autobiográfico, mas não solo, ela ilustra esse aspecto com uma anedota: "Dois anos atrás, eu fui convidada para participar com Nan Goldin de um painel sobre arte transgressiva. Eu estava falando com $\mathrm{Nan}$ no telefone e ela disse, 'A propósito Penny, o que é arte transgressiva?' Eu disse, 'Bem, Nan, arte transgressiva é como os acadêmicos chamam aquilo que eu e você chamamos de vida real!"”

Bad Reputation é o relato de Penny de como ela foi rotulada como bad girl aos treze anos e acabou fugindo de casa, indo parar no Reformatório aos quatorze anos. Ela narra como foi estuprada por um velho "amigo" aos dezesseis e sua mudança para Nova York aos dezesete, onde foi adotada pelas drag queens do East Village. A estrutura do trabalho, porém, constantemente relaciona suas anedotas pessoais com o quadro social mais amplo. Ela fala de todas as garotas rotuladas de bad girls que eventualmente acabaram viciadas em drogas ou prostituídas, e de todas as mulheres abusadas sexualmente - como na estória de Aileen Wournos, 
uma prostituta condenada à morte por matar sete homens. "Nós vivemos numa sociedade", diz Penny, "que não acredita que prostitutas possam ser estupradas, especialmente as mais ordinárias. Nós vivemos numa sociedade que não acredita que prostitutas possam ser abusadas sexualmente. Eu li que Aileen Wuornos esteve no reformatório quando tinha 14 anos, como eu. (...) Eu me pergunto porque minha vida e a dela acabaram por ser tão diferentes. (...) Durante muito tempo eu pensei que tinha sobrevivido a despeito de todas as coisas ruins que me aconteceram. Mas então eu comecei a considerar a possibilidade de que eu me tornei o que sou por causa de todas essas coisas".

Seu trabalho não é sobre sentir-se vítima, é sobre ser um alvo, como ela mesma coloca. Para Penny, o trabalho autobiográfico só faz sentido se pode conectar as suas experiências com as experiências de outras pessoas: "Eu não conto tudo como alguém faria numa confissão, eu conto apenas aquilo que me ancora ao mundo, aquilo que me torna semelhante aos outros, não aquilo que me faz diferente".

É interessante observar, entretanto, que tanto os críticos quanto os acadêmicos vêm persistentemente ignorando Penny Arcade. E embora ela seja largamente conhecida na Europa e na Austrália, ela enfrenta grandes dificuldades financeiras para produzir seu trabalho nos Estados Unidos, mesmo depois de 30 anos de vida artística. Seu trabalho é, em certo sentido, quase heróico, como ela mesma observa, não sem ironia, em $A$ Thousand and One Nights:

"Quem disse que não há mais boemia... olhe para vocês - vocês estão aqui... nesse buraco sujo no lower east side... e aqui estou eu, Penny Arcade, capacho profissional, a mais famosa artista performática de Nova York... famosa no mundo inteiro... e agora afundada em fracasso como uma verdadeira boemia e vocês... Sim, olhem para mim... como Joana d'Arc... sendo heróica... (...) sim e vocês, todos vocês... eu... vocês, nós... olhe para nós... os últimos remanescentes da boemia...”

\section{Conclusão}

A dificuldade - para não falar na impossibilidade - em definir a arte da performance como um gênero, mencionada no começo dessa apresentação, é igualmente válida no que se refere à autobiografia. Como bem observou Paul de Man, "empírica e teoreticamente a autobiografia presta-se pobremente à definição genérica; cada instância específica parece ser uma exceção à norma” (de Man, 1984 , p. 68). Tanto a autobiografia quanto a performance são processos abertos, compreendendo uma miríade de formas possíveis. Talvez por esta razão, a performance solo tenha se tornado um meio tão privilegiado para investigaçōes autobiográficas, abrindo novas possibilidades de representação do sujeito.

A autobiografia é geralmente entendida em termos de um movimento de singularização de uma vida exemplar, uma vida que por suas qualidades individuais e seu caráter único é merecedora de ser distinguida de outras vidas mais ordinárias. A narrativa de uma vida exemplar permite aos leitores/receptores reconhecer o particular no universal, a humanidade no sujeito individual. Por trás desta idéia está a suposição de que o sujeito em questão é um sujeito universal.

As vidas de Karen Finley, Peggy Shaw, e Penny Arcade dificilmente poderiam ser descritas como exemplares, ou como modelos que podem servir de espelho universal para a humanidade. Mulheres, lésbicas e artistas não correspondem exatamente à definição do sujeito universal que, de maneira geral, é construída como um sujeito masculino, branco e europeu. Seus trabalhos engajam sujeitos divididos, cujas identidades são marcadas por raça, classe, gênero e sexualidade. É somente em relação a esses significados culturais e históricos inscritos nos corpos dos sujeitos que qualquer identificação é possível. A performance solo autobiográfica, portanto, não conecta a humanidade a um todo, em nome de um sujeito universal, mas antes aponta as diferenças, as dissimilaridades, as des- 
continuidades. Ela revela como construção o que é assumido como "natural" ou "biológico" e, neste processo, revela o próprio sistema de representação, o discurso ideológico por meio do qual alguns sujeitos chegam a adquirir represen- tação e outros não. É, portanto, somente como identidades-em-diferença que qualquer identificação é possível, e que um sentido de identidade comunal pode ser alcançado.

\section{Referências bibliográficas}

ARCADE, P. New York Values e Bad Reputation. Manuscritos não publicados.

de MAN, P. "Autobiography as De-Facement". In: The Rethoric of Romanticism. Nova York, Columbia University Press, 1984.

BAKHTIN, M. Rabelais and His World. Bloomington, Indiana University Press, 1984.

BUTLER, J. "Imitation and Gender Subordination". In: The Lesbian and Gay Studies Reader. Nova York e Londres, Routledge, 1993, $1^{\mathrm{a}}$ ed. 1989. . Bodies that Matter: on the discursive limits of "sex". Nova York, Routledge, 1993.

CARR, C. On Edge: Performance at the end of the twentieth century. Hannover e Londres, University Press of New England, 1993.

FINLEY, K. “The Constant State of Desire: In: Shock Treatment. San Francisco, City Light Books, 1990. "Performances Strategies: In: MARRANCA \& DASGUPTA (eds.). Conversations on Art and Performance. Baltimore e Londres, John Hopkins University Press, 1999.

FOUCAULT, M. The History of Sexuality. Vol. 1. Nova York, Vintage Books, 1990.

HART, L. "Motherhood According to Karen Finley: The Theory of Total Blame". In: MARTIN, C. (ed.). A Sourcebook of Feminist Theatre and Performance. Nova York e Londres, Routledge, 1996.

LEJEUNE, P. On Autobiography. Minneapolis, University of Minnesota Press, 1989.

MARTIN, E. "Medical Metaphors of Women's Bodies: Menstruation and Menopause". In: CONBOY, MEDINA \& STANBURY, S. (eds.). Writing on the Body: Female Embodiment and Feminist Theory. Nova York, Columbia University Press, 1997.

PATRAKA, V.M. "Split Britches in Split Britches: Performing History, Vaudeville and the Everyday" In: HART \& PHELAN (eds.). Acting Out: Feminist Performances. Ann Arbor, Michigan University Press, 1993.

RÓMAN, D. Acts of Intervention. Bloomington e Indianapolis, Indiana University Press, 1998.

SHAW, P. Menopausal Gentleman. Manuscrito não publicado.

STAROBINSKI, J. “The Style of Autobiography”. In: OLNEY, J. (ed.). Autobiography: Essays Theoretical and Critical. New Jersey, Princeton University Press, 1972.

STILES, K. “Uncorrupted Joy: International Art Actions”. In: SCHIMMEL, P. Out of Actions. Nova York, Thames and Hudson, 1998. 